\title{
Clinical factors influencing the development of extracranial-intracranial bypass graft for steno-occlusive cerebrovascular disease
}

\author{
Shunsuke Nomura, MD, ${ }^{1}$ Koji Yamaguchi, MD, PhD, ${ }^{1}$ Tatsuya Ishikawa, MD, PhD, ${ }^{1}$ \\ Akitsugu Kawashima, MD, PhD, ${ }^{2}$ Yoshikazu Okada, MD, PhD, ${ }^{1}$ and Takakazu Kawamata, MD, PhD1 \\ 'Department of Neurosurgery, Tokyo Women's Medical University, Tokyo; and 'Department of Neurosurgery, Tokyo Women's \\ Medical University Yachiyo Medical Center, Chiba, Japan
}

\begin{abstract}
OBJECTIVE Effectively retaining the patency of the extracranial-intracranial $(\mathrm{ECIC})$ bypass is one of the most important factors in improving long-term results; however, the factors influencing bypass patency have not been discussed much. Therefore, the authors investigated factors influencing the development of the bypass graft.

METHODS In this retrospective study, the authors evaluated 49 consecutive hemispheres in 47 adult Japanese patients who had undergone ECIC bypass for chronic steno-occlusive cerebrovascular disease. To evaluate objectively the development of the $\mathrm{ECIC}$ bypass graft, the change in the area of the main trunk portion of the superficial temporal artery (STA) from before to after bypass surgery (postop/preop STA) was measured. Using the interquartile range (IQR), the authors statistically analyzed the factors associated with excellent ( $>3 \mathrm{rd}$ quartile) and poor development ( $<$ st quartile) of the bypass graft.
\end{abstract}

RESULTS The postop/preop STA ranged from 1.08 to 6.13 (median 1.97, IQR 1.645-2.445). There was a significant difference in the postop/preop STA between the presence and absence of concurrent diabetes mellitus $(p=0.0432)$ and hyperlipidemia (0.0069). Furthermore, logistic regression analysis revealed that only concurrent diabetes mellitus was significantly associated with poor development of the bypass graft $(p=0.0235)$.

CONCLUSIONS Diabetes mellitus and hyperlipidemia influenced the development of the ECIC bypass graft. In particular, diabetes mellitus is the only factor associated with poor development of the bypass graft.

https://thejns.org/doi/abs/10.3171/2018.11.FOCUS18500

KEYWORDS ECIC bypass; STA-MCA anastomosis; steno-occlusive cerebrovascular disease; patency; development

$\mathrm{T}$ HE discussion on the effectiveness of extracranialintracranial (ECIC) bypass for chronic steno-occlusive cerebrovascular disease continues worldwide, even after the Carotid Occlusion Surgery Study (COSS) in the United States. ${ }^{1,9}$ Although some studies such as the COSS have disproved the superior efficacy of the ECIC bypass over medical therapy, ${ }^{9}$ the Japanese EC-IC Bypass Trial (JET) revealed the procedure's effectiveness in a selected population with hemodynamic instability (data from the JET have not been reported in print, peerreviewed, English-language journals). ${ }^{8}$ Furthermore, other studies have also shown the long-term effectiveness of the ECIC bypass in the prevention of ischemic stroke. ., $^{2,10}$ These studies have reported good results or good patency with the bypass surgery.
Effectively retaining the patency of the ECIC bypass should be one of the most important factors in improving long-term results; however, factors influencing bypass patency have not been discussed much. Understanding those factors would directly contribute to the improvement of long-term results. We investigated bypass patency in 49 consecutive surgeries with a mean follow-up period of 34 months and the factors associated with the development of the bypass graft.

\section{Methods \\ Method}

This study was approved by our university's ethics board. Informed consent was obtained from all patients.

ABBREVIATIONS CBF = cerebral blood flow; COSS = Carotid Occlusion Surgery Study; CVR = cerebrovascular reactivity; ECIC = extracranial-intracranial; IQR = interquartile range; JET = Japanese EC-IC Bypass Trial; MCA = middle cerebral artery; STA = superficial temporal artery; TOF = time of flight.

SUBMITTED September 26, 2018. ACCEPTED November 7, 2018.

INCLUDE WHEN CITING DOI: 10.3171/2018.11.FOCUS18500. 
We evaluated 49 consecutive hemispheres in 47 Japanese patients (31 men and 16 women, age range 39-74 years) who had been diagnosed with chronic arteriosclerotic internal carotid artery (ICA) occlusion or middle cerebral artery (MCA) occlusion or stenosis and had undergone direct bypass at our hospital in the period between April 2013 and December 2015. We retrospectively investigated the patency of the ECIC bypass as a follow-up evaluation of the long-term results of revascularization and collected other clinical information including major arteriosclerotic complications by reviewing the medical records. The final status of the enrolled patients is presented as determined between April 2016 and March 2018. Patients with conditions related to aneurysms, brain tumors, or rescue bypass in the acute stage were not included in the study. Two patients were excluded because they lived far away and were scheduled for postoperative follow-ups at other clinics.

\section{Surgical Indication for ECIC Bypass}

The indications for ECIC bypass were based on the overall evaluation including symptoms, hemodynamic instability, and resistance to medication, basically referring to the JET criteria. Cerebral blood flow (CBF) was measured using cold xenon-CT, and cerebrovascular reactivity (CVR) was measured via the acetazolamide loading test with an increase in CBF defined as the percentage increase in $\mathrm{CBF}$ over resting $\mathrm{CBF}$, as previously described..$^{12}$

\section{Surgical Procedures and Postoperative Management}

All patients underwent superficial temporal artery (STA)-MCA double anastomoses to the supra- and infrasylvian portions of the MCAs $\left(\mathrm{M}_{3}\right.$ or $\left.\mathrm{M}_{4}\right)$ while under general anesthesia. An antiplatelet drug was administered until the day of surgery and restarted on the 5th postoperative day. Intraoperatively, patency of the bypass was confirmed using indocyanine green videography and bidirectional Doppler ultrasonography. Immediately following surgery, CBF was evaluated with xenon-CT while the patient remained sedated with propofol. Sedation was stopped after evaluation of hyperperfusion, as previously described., ${ }^{7,12}$ Almost all patients were discharged 7-10 days after surgery and followed-up in the outpatient clinic.

\section{Evaluating the Development of the ECIC Bypass Graft}

Development of the ECIC bypass graft was evaluated on MRI (time of flight [TOF]) before and after surgery by measuring the area of the main trunk portion of the STA used as a graft (Fig. 1). The area was calculated using the following equation: $\pi \times$ the major axis $\times$ the minor axis. To measure the bypass graft after surgery, we used the TOF sequence in which the main trunk of the STA after revascularization had expanded the most just above the zygomatic arch at the last MRI session (defined as postop STA). The area of pre-revascularization was also measured in the same manner at the same portion as the postop STA (defined as preop STA).

The ratio of postop STA to preop STA (postop/preop STA) was set as a score indicating the development of the ECIC bypass graft. Its median value with and without each comorbidity was compared. Furthermore, it was classified

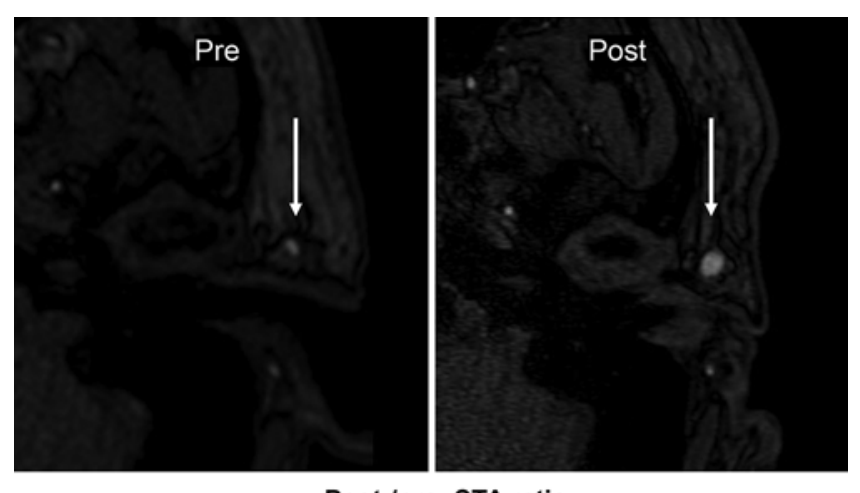

Post-/pre- STA ratio

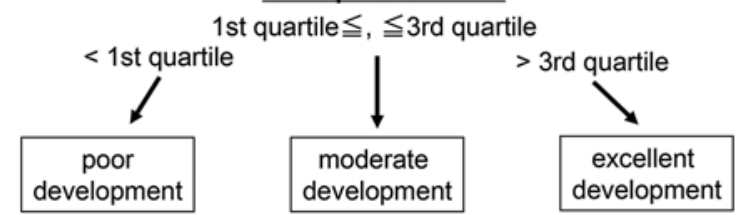

FIG. 1. Method of evaluating the development of the graft (arrows) in an $\mathrm{ECIC}$ bypass.

into three groups using the interquartile range (IQR): excellent development ( $>$ 3rd quartile), moderate development ( $\geq 1$ st quartile and $\leq 3$ rd quartile), and poor development $(<1$ st quartile). The factors associated with excellent and poor development of the bypass graft were statistically analyzed, and we included the following factors: age, comorbidities, steal phenomenon, size of preoperative STA, and follow-up period.

\section{Statistical Analysis}

Age and postop/preop STA were calculated on a nonparametric continuous scale. The Mann-Whitney U-test and Kruskal-Wallis tests were used to compare age and postop/ preop STA with or without each comorbidity. Univariate logistic regression analysis was conducted to analyze the factors associated with poor development and excellent development of the bypass graft. The level of significance was set at $\mathrm{p}<0.05$. A commercially available software package (JMP Pro 13, SAS Institute) was used for the analyses.

\section{Results}

\section{Background of Enrolled Patients}

In 49 consecutive hemispheres in 47 patients, major comorbidities were as shown in Table 1. Hypertension was the most common comorbidity, followed by hyperlipidemia, diabetes mellitus, chronic kidney disease, coronary heart disease, and arteriosclerosis obliterans.

\section{Short- and Middle-Term Results}

Within 1 month following surgery, cerebral infarction (asymptomatic) occurred in one hemisphere (2\%) and cerebral hemorrhage due to hyperperfusion occurred in one hemisphere (2\%; Table 2). At a mean follow-up of 34 months, no recurrent stroke was observed.

\section{Patency of ECIC Bypass Graft and Postop/Preop STA}

All STA-MCA double anastomoses were patent 
TABLE 1. Preoperative characteristics associated with 49 consecutive hemispheres

\begin{tabular}{lc}
\hline \multicolumn{1}{c}{ Variable } & Value \\
\hline Sex & \\
\hline Male & 33 \\
\hline Female & 16 \\
\hline Median patient age in yrs (IQR) & $62(50.5-66)$ \\
\hline Hypertension & 34 \\
\hline DM & 19 \\
\hline Hyperlipidemia & 24 \\
\hline CKD & 9 \\
\hline ASO & 2 \\
\hline CAD & 8 \\
\hline
\end{tabular}

ASO $=$ arteriosclerosis obliterans; $\mathrm{CAD}=$ coronary artery disease $\mathrm{CKD}=$ chronic kidney disease; $\mathrm{DM}=$ diabetes mellitus.

Values for sex, hypertension, DM, hyperlipidemia, CKD, ASO, and CAD represent number of hemispheres.

through the observation period. The postop/preop STA ranged from 1.08 to 6.13 (median 1.97, IQR 1.645-2.445). No patient had a decrease in this ratio; therefore, poor development of the bypass graft was defined as a value less than 1.645. Excellent development was defined as a value greater than 2.445 .

There was a significant difference in the postop/preop STA between the presence and absence of a history of diabetes mellitus $(\mathrm{p}=0.0432)$ and hyperlipidemia $(0.0069)$, as shown in Table 3. The other comorbidities showed no significant difference.

Furthermore, logistic regression analysis revealed that only concurrent diabetes mellitus was significantly associated with poor development of the bypass graft ( $\mathrm{p}=$ 0.0235 ), as shown in Table 4. Also, none of the comorbidities were significantly associated with excellent development of the bypass graft, as shown in Table 5, although the absence of hyperlipidemia had a statistically marginal effect (0.0513).

\section{Discussion}

\section{Factors Influencing Bypass Patency}

Bypass patency was retained in all the patients under our management, and none experienced recurrent cerebral infarction in a mean follow-up period of 34 months. Our

TABLE 2. Short-term and middle-term outcomes following ECIC bypass

\begin{tabular}{lcc}
\hline \multicolumn{1}{c}{ Result } & $\begin{array}{c}\text { Outcome w/in 1 Month } \\
\text { After Surgery }\end{array}$ & $\begin{array}{c}\text { Outcome at Mean } \\
\text { FU of 34 Mos }\end{array}$ \\
\hline Infarction & $1(2 \%)$, asymptomatic & $0(0 \%)$ \\
\hline Hemorrhage & $1(2 \%) \dagger$ & $0(0 \%)$ \\
\hline Death & $0(0 \%)$ & $0(0 \%)$ \\
\hline Bypass patency & $49(100 \%)$ & $49(100 \%)$ \\
\hline
\end{tabular}

$\mathrm{FU}=$ follow-up.

${ }^{*}$ Range 7-52 months.

$\dagger$ Postoperative hemorrhage caused by hyperperfusion
TABLE 3. Median value of postop/preop STA with or without each comorbidity

\begin{tabular}{lccc}
\hline \multirow{2}{*}{ Comorbidity } & \multicolumn{2}{c}{ Median Postop/Preop STA (IQR) } & $p$ \\
\cline { 2 - 3 } & w/ Comorbidity & w/o Comorbidity & Value \\
\hline Hypertension & $1.91(1.58-2.49)$ & $2.15(1.75-2.23)$ & 0.5081 \\
\hline DM & $1.88(1.37-2.36)$ & $2.15(1.73-2.74)$ & 0.0432 \\
\hline Hyperlipidemia & $1.76(1.50-2.04)$ & $2.22(1.82-2.85)$ & 0.0069 \\
\hline CKD & $1.91(1.61-2.72)$ & $1.985(1.64-2.40)$ & 0.5965 \\
\hline ASO & $3.23(1.91-4.55)$ & $1.97(1.63-2.44)$ & 0.2886 \\
\hline CAD & $2.35(1.91-3.85)$ & $1.89(1.63-2.4)$ & 0.1719 \\
\hline
\end{tabular}

Boldface type indicates statistical significance.

main analysis revealed that diabetes mellitus and hyperlipidemia are significant factors influencing bypass patency in ECIC bypass for steno-occlusive cerebrovascular disease. In particular, our findings showed that the coexistence of diabetes mellitus was significantly associated with poor development of the bypass graft. The "level" or "extent" of the development in the ECIC bypass graft has been little discussed in previous major studies such as the COSS or JET. 9 To our knowledge, only one study has mentioned the factors influencing bypass patency. ${ }^{6}$ In that report, these factors were postoperative hyperperfusion and smoking, whereas diabetes mellitus was not found to be associated with bypass patency. Moreover, the authors did not mention the other concurrent diseases such as hyperlipidemia. However, our study, which focused on concurrent diseases, showed that diabetes mellitus was the only significant factor and hyperlipidemia was a statistically marginal factor associated with bypass patency. A good understanding of the factors associated with bypass patency is extremely important for long-term results in bypass surgery. Diabe-

TABLE 4. Factors associated with poor development of the bypass graft

\begin{tabular}{|c|c|c|c|}
\hline Factor & $\begin{array}{c}\text { Poor } \\
\text { Development }\end{array}$ & $\begin{array}{c}\text { Non-Poor } \\
\text { Development }\end{array}$ & $\begin{array}{c}p \\
\text { Value }\end{array}$ \\
\hline No. of hemispheres & 12 & 37 & \\
\hline $\begin{array}{l}\text { Median age in yrs } \\
\quad(I Q R)\end{array}$ & $62.5(51-68)$ & $61(50-66)$ & 0.8536 \\
\hline Hypertension & 10 & 24 & 0.2090 \\
\hline DM & 8 & 11 & 0.0235 \\
\hline Hyperlipidemia & 8 & 16 & 0.1556 \\
\hline CKD & 2 & 7 & 0.8598 \\
\hline ASO & 0 & 2 & 0.2833 \\
\hline CAD & 1 & 7 & 0.3603 \\
\hline Steal phenomenon & 4 & 11 & 0.8149 \\
\hline $\begin{array}{l}\text { Median size of } \\
\text { preop STA } \times \pi \text { in } \\
\mathrm{mm}^{2}(\mathrm{IQR})\end{array}$ & $1.65(1.30-1.97)$ & $1.46(1.21-1.90)$ & 0.5343 \\
\hline $\begin{array}{l}\text { Median FU in mos } \\
\quad(I Q R)\end{array}$ & $31(28-35.5)$ & $36(28.5-44)$ & 0.1792 \\
\hline
\end{tabular}

Logistic regression analysis was performed. Boldface type indicates statistical significance. 
TABLE 5. Factors associated with excellent development of the bypass graft

\begin{tabular}{lccc}
\hline \multicolumn{1}{c}{ Factor } & $\begin{array}{c}\text { Excellent } \\
\text { Development }\end{array}$ & $\begin{array}{c}\text { Non-Excellent } \\
\text { Development }\end{array}$ & $\begin{array}{c}p \\
\text { Value }\end{array}$ \\
\hline No. of hemispheres & 12 & 37 & \\
\hline $\begin{array}{l}\text { Median age in yrs } \\
(\text { IQR })\end{array}$ & $60(50.8-64.8)$ & $63(50.5-66)$ & 0.8116 \\
\hline Hypertension & 9 & 25 & 0.6228 \\
\hline DM & 3 & 16 & 0.2494 \\
\hline Hyperlipidemia & 3 & 21 & 0.0513 \\
\hline CKD & 4 & 5 & 0.1421 \\
\hline ASO & 1 & 1 & 0.4261 \\
\hline CAD & 3 & 5 & 0.3676 \\
\hline $\begin{array}{l}\text { Steal phenomenon } \\
\text { Median size of } \\
\text { preop STA } \times \pi \text { in } \\
\text { mm }{ }^{2} \text { (IQR) }\end{array}$ & $1.36(1.16-1.51)$ & $1.65(1.26-2.03)$ & 0.3345 \\
\hline $\begin{array}{l}\text { Median FU in mos } \\
(I Q R)\end{array}$ & $37(27.75-46.5)$ & $32(28-42.5)$ & 0.3554 \\
\hline
\end{tabular}

Logistic regression analysis was performed.

tes mellitus is known to be a major component in arteriosclerosis; thus, it can cause hardening of the bypass graft, leading to disturbances in enlargement of the bypass graft.

\section{Role of Hemodynamic Parameter in Bypass Graft Development}

A previous study has demonstrated that a CVR measurement is one of the factors useful in evaluating the hemodynamic effect of surgical revascularization; 5 therefore, we hypothesized that a hemodynamic parameter such as CVR might influence the development of the bypass graft. However, a preoperative steal phenomenon $(\mathrm{CVR}<$ 0 ) was not significantly associated with the development of the bypass graft in our analysis. We suggest that CVR indicates vasoreactivity, and it may be less linked to the development of the bypass graft with respect to the hemodynamic parameters because development of the bypass probably depends on how much $\mathrm{CBF}$ or cerebral blood volume is in demand. The hemodynamic parameters used in our study were limited, and further investigations are needed to verify how hemodynamic parameters influence development of the bypass graft.

\section{Follow-Up Period and Size of Preoperative STA in Bypass Graft Development}

According to our surgical experience, a longer followup period and larger preoperative STA area seemed to influence the development of the bypass graft. However, the data in our series showed a negative correlation between bypass graft development and follow-up period and size of preoperative STA, probably owing to an insufficient sample size. In the future, the role of these factors needs to be confirmed by further studies involving an adequate sample size.

\section{Significance of Bypass Surgery}

Although the superior effectiveness of bypass surgery over medical therapy was disproved by the COSS study, ${ }^{9}$ subsequent single-center series have shown good shortterm and long-term outcomes for bypass surgery in Japan and Europe..$^{4,10,11}$ Although patient backgrounds could have differed in those single-center studies, it is extremely important to develop a technically good, patent bypass and to lower perioperative morbidities, which could lead to differences in procedural effectiveness between studies. We must consider the preoperative risk factors relating to ischemic events or symptomatic hyperperfusion. ${ }^{3,12}$ Furthermore, we stress that understanding the factors that influence development of the bypass graft may contribute to improving the significance of ECIC bypass for stenoocclusive cerebrovascular disease, as shown in our study.

\section{Study Limitations}

There were some limitations to our study. First, our evaluation of the development of the bypass graft used comparisons of the area of the STA measured on TOF MRI. Postoperative angiography could not be routinely conducted because of the unavailability of patient consent. But our measurement using the area of the STA on TOF images may be useful because we could evaluate the development of the bypass graft objectively and noninvasively. Second, we analyzed the current status and the history of diabetes mellitus using retrospective data; therefore, we could not determine how the current control of diabetes mellitus influences bypass patency. Furthermore, the number of patients included in this study may be relatively small, but they are sufficient in offering preliminary data to show the significant factors influencing bypass patency. In the future, a larger study with an elaborate design may be needed to determine these factors.

\section{Conclusions}

Our study demonstrated that concurrent diabetes mellitus and hyperlipidemia are significant factors influencing development of the bypass graft in ECIC bypass for stenoocclusive cerebrovascular disease. In particular, the coexistence of diabetes mellitus was significantly associated with poor development of the bypass graft. Enhancing the surgical technique, reducing perioperative comorbidities, and understanding the factors associated with development of the bypass graft would surely improve the results of bypass surgery and enhance the significance of the bypass surgical technique in this context.

\section{References}

1. Bauer AM, Bain MD, Rasmussen PA: Chronic cerebral ischemia: where "evidence-based medicine" fails patients. World Neurosurg 84:714-718, 2015

2. Chen X, Lin CL, Su YC, Chen KF, Lai SW, Wei ST, et al: Risk of subsequent stroke, with or without extracranialintracranial bypass surgery: a nationwide, retrospective, population-based study. J Neurosurg [epub ahead of print June 1, 2018. DOI: 10.3171/2017.12.JNS172178]

3. Horn P, Scharf J, Peña-Tapia P, Vajkoczy P: Risk of intraoperative ischemia due to temporary vessel occlusion during 
standard extracranial-intracranial arterial bypass surgery. $\mathbf{J}$ Neurosurg 108:464-469, 2008

4. Kuroda S, Kawabori M, Hirata K, Shiga T, Kashiwazaki D, Houkin K, et al: Clinical significance of STA-MCA double anastomosis for hemodynamic compromise in post-JET/ COSS era. Acta Neurochir (Wien) 156:77-83, 2014

5. Mandell DM, Han JS, Poublanc J, Crawley AP, Fierstra J, Tymianski M, et al: Quantitative measurement of cerebrovascular reactivity by blood oxygen level-dependent MR imaging in patients with intracranial stenosis: preoperative cerebrovascular reactivity predicts the effect of extracranialintracranial bypass surgery. AJNR Am J Neuroradiol 32:721-727, 2011

6. Matano F, Murai Y, Tateyama K, Tamaki T, Mizunari T, Matsukawa H, et al: Long-term patency of superficial temporal artery to middle cerebral artery bypass for cerebral atherosclerotic disease: factors determining the bypass patent. Neurosurg Rev 39:655-661, 2016

7. Nomura S, Yamaguchi K, Ishikawa T, Kawashima A, Okada Y, Kawamata T: Factors of delayed hyperperfusion and the importance of repeated cerebral blood flow evaluation for hyperperfusion after direct bypass for moyamoya disease. World Neurosurg 118:e468-e472, 2018

8. Ogasawara K, Ogawa A: [JET study (Japanese EC-IC Bypass Trial).] Nihon Rinsho 64 (Suppl 7):524-527, 2006 (Jpn)

9. Powers WJ, Clarke WR, Grubb RL Jr, Videen TO, Adams HP Jr, Derdeyn CP: Extracranial-intracranial bypass surgery for stroke prevention in hemodynamic cerebral ischemia: the Carotid Occlusion Surgery Study randomized trial. JAMA 306:1983-1992, 2011 (Erratum in JAMA 306:2672, 2011)

10. Sandow N, von Weitzel-Mudersbach P, Rosenbaum S, König S, Buchert R, Mehl SR, et al: Extra-intracranial standard bypass in the elderly: perioperative risk, bypass patency and outcome. Cerebrovasc Dis 36:228-235, 2013

11. von Weitzel-Mudersbach P, Andersen G, Rosenbaum S: Low morbidity after extracranial-intracranial bypass operation. The Danish Extracranial-Intracranial Bypass Study: a nationwide survey. Cerebrovasc Dis 45:252-257, 2018

12. Yamaguchi K, Kawamata T, Kawashima A, Hori T, Okada Y: Incidence and predictive factors of cerebral hyperperfusion after extracranial-intracranial bypass for occlusive cerebrovascular diseases. Neurosurgery 67:1548-1554, 2010

\section{Disclosures}

The authors report no conflict of interest concerning the materials or methods used in this study or the findings specified in this paper.

\section{Author Contributions}

Conception and design: Yamaguchi, Nomura. Acquisition of data: Nomura, Ishikawa, Kawashima. Analysis and interpretation of data: Yamaguchi, Nomura, Ishikawa. Drafting the article: Nomura. Critically revising the article: Yamaguchi. Reviewed submitted version of manuscript: all authors. Approved the final version of the manuscript on behalf of all authors: Yamaguchi. Statistical analysis: Nomura. Administrative/technical/material support: Okada, Kawamata. Study supervision: Kawashima, Okada, Kawamata.

\section{Correspondence}

Koji Yamaguchi: Tokyo Women's Medical University, Tokyo, Japan.yamaguchi.koji@twmu.ac.jp. 